
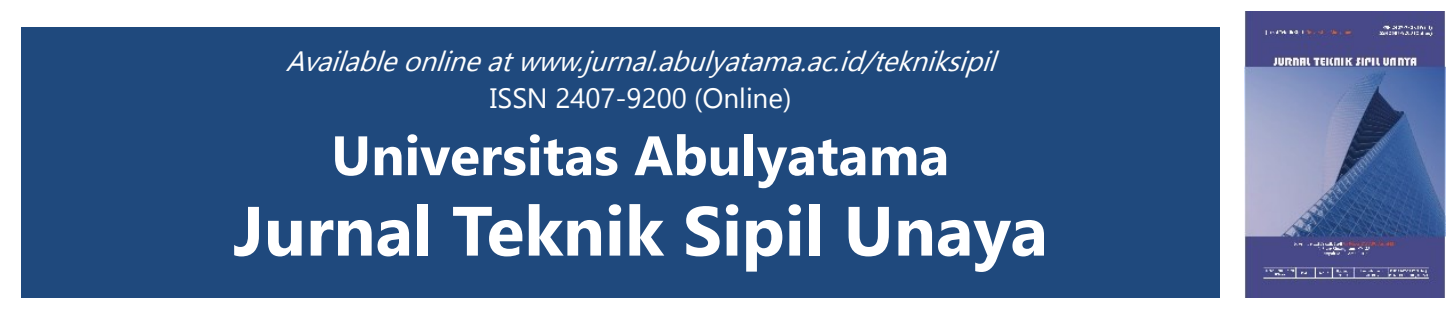

\title{
Analisa Produktivitas Tenaga Kerja Pada Pekerjaaan Rangka Atap
}

\author{
Mulyadi $^{1 *}$, Hasnawati ${ }^{1}$, Muhammad Ridha ${ }^{2}$ \\ ${ }^{1}$ STKIP Bina Bangsa Meulaboh, Jl. Lintas Barat Sumatera, Peunaga Cut Ujong, Meureubo, \\ 23681, Aceh, Indonesia \\ ${ }^{2}$ Program Studi Teknik Sipil, Fakultas Teknik, Universitas Abulyatama, Jl. Blang Bintang \\ Lama Km 8,5 Lampoh Keude Aceh Besar, 23372, Indonesia \\ * Email korespondensi: mul_young@yahoo.co.id
}

Diterima 2 Mei 2019; Disetujui 2 Juli 2019; Dipublikasi 31 Juli 2019

\begin{abstract}
Productivity is an important factor in determining the success of a construction work. Increased productivity will reduce work time, and that means it will reduce costs. In general, the value of productivity is determined by the factor of the volume of work, implementation time, and the number of workers. In order to get the job done well, a planning effort is needed by paying attention to these factors. For this reason, this study was conducted to determine the value of productivity in one component of building construction work, namely lightweight steel roof truss work. The object of study was the work of lightweight steel roof truss 4 (four) project sites, namely the $4 \times 25$ Shop Houses Construction Project in Meulaboh, West Aceh, the Building of the Rector \& Administration Bureau Building of STKIP Bina Bangsa Getsempena Banda Aceh, the Construction of the Getsempena Lhoksukon North Aceh STIKES Building and the Construction of North Aceh RIKI STIKes Building, Bina Nusantara Idi, East Aceh. The roof truss material used is type C Truss 750.75 Thickness. The volume of roof truss work is planned to be $2022.38 \mathrm{~m} 2$. The study was conducted through field observations by directly recording the volume of work, the duration of each stage of work, and the number of workers involved. The results of the analysis show that the productivity value for roof truss works is obtained by an average of $2,062 \mathrm{m2} /$ hour or $16,499 \mathrm{~m} 2$ / day. In the implementation of roof truss work, the amount of labor used is the same in all segments, so the value of productivity tends to be determined by the magnitude of the ratio between the volume of work and the effective time of implementation. Thus, if the amount of work volume can be completed in a shorter time then the value of productivity will increase
\end{abstract}

Keywords: productivity, labor, roof truss work

\begin{abstract}
Abstrak: Produktivitas merupakan salah satu faktor penting dalam menentukan keberhasilan suatu pekerjaan konstruksi. Peningkatan produktivitas akan mengurangi waktu pekerjaan, dan itu berarti akan mereduksi biaya. Secara umum, nilai produktivitas ditentukan oleh faktor besaran volume pekerjaan, waktu pelaksanaan, dan jumlah tenaga kerja. Agar pekerjaan dapat diselesaikan dengan baik, diperlukan upaya perencanaan dengan memperhatikan faktor-faktor tersebut. Untuk itu, penelitian ini dilakukan untuk mengetahui nilai produktivitas pada salah satu komponen pekerjaan bangunan gedung yaitu pekerjaan rangka atap baja ringan. Objek yang diteliti adalah pekerjaan rangka atap baja ringan 4 (empat) lokasi proyek yaitu Proyek Pembangunan Ruko 4 x 25 di Meulaboh Aceh Barat, Pembangunan Gedung Biro Rektorat \& Administrasi STKIP Bina Bangsa Getsempena Banda Aceh, Pembangunan
\end{abstract}


Gedung Kuliah STIKes Getsempena Lhoksukon Aceh Utara dan Pembangunan Gedung Rektorat STIKes Bina Nusantara Idi Aceh Timur. Material bahan rangka atap yang digunakan adalah jenis $\mathrm{C}$ Truss 75 Tebal 0,75. Volume pekerjaan rangka atap direncanakan seluas 2022,38 $\mathrm{m} 2$. Penelitian dilakukan melalui observasi lapangan dengan mencatat langsung volume pekerjaan, durasi setiap tahap pekerjaan, dan jumlah tanaga kerja yang terlibat. Hasil analisis menunjukkan bahwa nilai produktivitas untuk pekerjaan rangka atap diperoleh rata-rata sebesar 2,062 m2/jam atau 16,499 m2/hari. Pada pelaksanaan pekerjaan rangka atap, jumlah tenaga kerja yang digunakan sama pada seluruh segmen, sehingga nilai produktivitas cenderung ditentukan oleh besaran rasio antara volume pekerjaan dan waktu efektif pelaksanaan. Dengan demikian, bila jumlah volume pekerjaan dapat diselesaikan dalam waktu yang lebih singkat maka nilai produktivitas akan meningkat.

Kata kunci : produktivitas, tenaga kerja, pekerjaan rangka atap.

Sumber daya adalah faktor penentu keberhasilan kontruksi tersebut. Sumber daya yang berpengaruh dalam proyek terdiri dari pekerja (manusia), bahan, mesin, uang dan metode pekerjaannya. Pada pekerjaan kontruksi sumber daya manusia salah satu faktor yang terpenting. Pekerjaan apapun apabila tidak ditunjang dengan sumber daya manusia (SDM) yang tepat dalam hal kualitas dan produktivitas, tidak akan memberikan hasil yang memuaskan dan maksimal dalam sebuah proyek. Penggunaan sumber daya manusia yang kurang efisien/bijaksana bisa berakibat kerugian yang besar pada proyek kontruksi.

Upaya mengatur atau mengelola penggunaan SDM agar tepat, kontraktor harus mengetahui tingkat produktivitas masing-masing pekerja. Proyek kontruksi yang berhasil sangat memerlukan produktifikas tenaga kerja yang sangat baik/tepat. Besarnya keuntungan atau kerugian suatu proyek dipengaruhi oleh produktivitas tenaga kerja. Pelaksanaan dilapangan, ini kadang-kadang dapat terjadi karena tenaga kerja kurang efektif dalam pekerjaannya. Contoh tindakan yang menyebabkan pekerjaan tidak efektif termasuk pengangguran, mengobrol, makan, merokok, istirahat, yang semuanya dilakukan selama jam kerja.

Selain kegiatan yang kurang efektif di atas yang menyebabkan hambatan produktivitas, masih ada faktor lain yang mempengaruhi produktivitas tenaga kerja. Faktor-faktor ini termasuk kondisi lapangan dan fasilitas pendukung, keterampilan karyawan, faktor usia atau usia pekerja, kesesuaian upah, pengalaman dalam pekerjaan, kesehatan pekerja, koordinasi dan perencanaan, jenis kontrak kerja, manajerial atau manajemen lapangan. Variabel-variabel ini adalah hal-hal yang tentunya menjadi variabel yang mempengaruhi produktivitas kerja. Oleh karena itu, dalam upaya untuk menganalisis produktivitas tenaga kerja harus dipertimbangkan variabel yang mungkin mempengaruhi tingkat produktivitas.

Penyelesaian konstruksi bangunan dilakukan secara bertahap sesuai dengan komponen kerja. Secara umum, komponenkomponen ini dapat dikelompokkan menjadi komponen struktural dan komponen nonstruktural. Komponen struktural berhubungan dengan bagian konstruksi yang berfungsi untuk menahan dan memikul beban bangunan, sedangkan komponen non-struktural terkait 
dengan komponen arsitektur dan utilitas bangunan. Pelaksanaan pekerjaan konstruksi yang terencana adalah salah satu upaya untuk mencapai keberhasilan penyelesaian proyek konstruksi. Perencanaan umumnya terkait dengan penyediaan sumber daya proyek, seperti tenaga kerja, bahan dan peralatan, dan berbagai sumber daya proyek lainnya. Pada tahap implementasi, sinergi antara sumber daya ini akan menghasilkan produktivitas kerja, yang akan menjadi salah satu tolok ukur untuk keberhasilan penyelesaian suatu proyek.

Peningkatan atau penurunan nilai produktivitas sangat ditentukan oleh kemampuan tenaga kerja yang terlibat dalam menyelesaikan pekerjaan dalam jangka waktu tertentu. Produktivitas akan meningkat jika volume pekerjaan dapat diselesaikan lebih cepat daripada target waktu yang ditentukan dan sebaliknya. Secara umum, nilai produktivitas ditentukan oleh faktor jumlah volume pekerjaan, waktu pelaksanaan, dan jumlah pekerja.

Studi tentang produktivitas diperlukan terutama jika dikaitkan dengan proses standardisasi material, tenaga kerja dan persyaratan peralatan untuk suatu pekerjaan. Standar ini akan menjadi panduan bagi perencana, baik dalam perencanaan anggaran dan dalam merencanakan waktu penyelesaian proyek. Berdasarkan latar belakang ini, penelitian ini bertujuan untuk menganalisis nilai produktivitas di salah satu komponen nonstruktural suatu bangunan. Secara khusus, penelitian dilakukan pada komponen penutup atap.

Berdasarkan permasalahan tersebut, penulis melakukan penelitian tentang produktivitas tenaga kerja pada empat lokasi yaitu :

1. Proyek pembangunan Ruko $4 \times 25 m$ di Meulaboh Aceh Barat,

2. Gedung Biro Rektorat \& Administrasi STKIP Bina Bangsa Getsempena Banda Aceh,

3. Gedung Kuliah STIKes Getsempena Lhoksukon Aceh Utara, dan

4. Gedung Rektorat STIKes Bina Nusantara Idi Aceh Timur.

\section{KAJIAN PUSTAKA}

Secara umum, sebuah konstruksi bangunan gedung dapat digolongkan menjadi komponen structural dan komponen non-struktural (Anonim,2007). Komponen structural berkaitan dengan bagian dari konstruksi yang berfungsi menahan dan meneruskan beban bangunan, sedang komponen non-struktural berkaitan dengan komponen arsitektur dan utilitas bangunan. Pelaksanaan pekerjaan konstruksi yang terencana dengan baik merupakan salah satu upaya mencapai kesuksesan penyelesaian sebuah proyek konstruksi. Perencanaan tersebut umumnya berkaitan dengan penyediaan sumber daya proyek, seperti tenaga kerja, material dan peralatan, dan berbagai sumber daya proyek lainnya. Pada tahap pelaksanaan, hubungan antara sumber daya manusia akan menghasilkan sebuah produktivitas kerja, yang akan menjadi salah satu tolok ukur dalam penyelesaian sebuah kegiatan proyek.

Peningkatan atau penurunan nilai produktivitas sangat ditentukan oleh kemampuan pekerja yang terlibat dalam menyelesaikan suatu 
proyek dalam waktu tertentu. Produktivitas akan meningkat jika volume sebuah pekerjaan dapat lebih cepat terselesaikan dari target waktu yang direncanakan awal dan demikian pula sebaliknya. Secara umum, nilai produktivitas ditentukan oleh faktor besaran volume pekerjaan, waktu pelaksanaan, dan jumlah tenaga kerja. Agar pekerjaan dapat diselesaikan dengan baik, dan cepat diperlukan perencanaan yang baik dengan memperhatikan faktor-faktor tersebut diatas.

Kajian mengenai produktivitas sangat diperlukan terutama bila dikaitkan dengan proses standarisasi kebutuhan material, tenaga kerja, dan peralatan untuk sebuah pekerjaan. Standar tersebut akan menjadi pedoman bagi seorang perencana, baik dalam perencanaan anggaran maupun dalam perencanaan waktu penyelesaian sebuah proyek. Berdasarkan latarbelakang tersebut, penelitian ini ditujukan untuk menganalisis nilai produktivitas pada salah satu komponen non-struktural bangunan gedung. Secara spesifik, kajian dilakukan pada komponen penutup atap.

\section{Kontruksi Atap}

Konstruksi bangunan gedung terdiri dari sejumlah komponen yang secara umum dapat dikelompokkan dalam komponen structural dan komponen non-struktural. Konstruksi atap merupakan salah satu komponen pembentuk sebuah bangunan gedung. Secara umum atap berfungsi sebagai penutup seluruh ruangan yang ada dibawahnya terhadap pengaruh panas, hujan, debu, kotoran, angin, dan sebagainya. Berdasarkan tipe dan jenis atap antara lain atap datar (plandak), atap sandar, atap pelana, atap limasan dan atap gabungan. Pemilihan bentuk dan jenis atap harus disesuaikan dengan bentuk bangunan dibawahnya, iklim/cuasa setempat, biaya, serta bahan bangunan yang tersedia didaerah tersebut (Kusjuliadi, 2007).

Pada dasarnya, ada dua komponen utama sebagai penyusun atap, yaitu struktur atap dan penutup atap. Struktur atap merupakan susunan rangka batang yang berfungsi sebagai pendukung atau penahan beban penutup atap. Struktur atap meliputi kuda-kuda atap dan rangka atap. Bahan konstruksi rangka atap antara lain kayu, baja ringan, beton bertulang dan bamboo. Masingmasing bahan tersebut mempunya kelebihan dan kekurangannya tersendiri.

\section{Produktivitas}

Produktivitas dapat diartikan sebagai perbandingan antara output (hasil produksi) terhadap input (komponen produksi : tenagakerja, bahan, peralatan, dan waktu). Jadi dalam analisis produktivitas dapat dinyatakan sebagai rasio antara output terhadap input dan waktu (jam atau hari). Hansen, 2009 Produktivitas bisa kita dapatkan dengan membagi volume pekerjaan yang telah terpasang dengan jumlah mandays yang dibutuhkan untuk penyelesaian pekerjaan sebesar volume tersebut. Produktivitas biasanya dihitung per bulan, walaupun bisa juga dihitung per minggunya. Produktivitas dapat dihitung dengan menggunakan persamaan:

Total mandays $=$ Hari kerja (hari) $\mathrm{x}$ Jumlah pekerja (orang)

Produktivitas $=$ Volume pekerjaan $(\mathrm{m} 2) /$ Mandays (orang.hari / OH) 
Pekerjaan penutup atap meliputi kudakuda/rangka dan penutup atap. Bahan kuda-kuda atap ada dua jenis yaitu bahan kayu dan bahan baja ringan. Bahan penutup atap antara lain bahan semen (genteng semen) dan seng (seng genteng).Angka produktivitas tenaga kerja terhadap pekerjaan struktur rangka atap baja ringan terhadap pekerjaan rangka atap kayu ada sedikit perbedaan, yaitu nilai produktivitas tenaga kerja terhadap pekerjaan rangka atap baja ringan lebih besar dari pada nilai produktivitas tenaga kerja terhadap pekerjaan rangka atap kayu (Tisnawan dan Hadi, 2016).

Pengukuran produktivitas tenaga kerja menurut sistem penghasilan perorangan / per orang atau per jam secara luas diterima, tergantung dari sudut pandang pengawasan harian, pengukuran ini umumnya tidak memuaskan, karena variasi dalam jumlah yang diperlukan untuk menghasilkan satu unit produk. berbeda. Oleh karena itu, metode pengukuran waktu kerja (jam, hari atau tahun) digunakan.

\section{METODE PENELITIAN}

\section{Objek Penelitian}

Penelitian ini dilakukan secara khusus pada komponen kuda-kuda atau rangka penutup atapnya saja. Penelitian mengambil lokasi pada proyek Pembangunan Gedung dan Ruko di Aceh. Bahan rangka atap yang digunakan adalah jenis C Truss 75 Tebal 0.75 dengan total volume yang direncanakan seluas 2022,38 $\mathrm{m}^{2}$. Lingkup observasi difokuskan pada 4 lokasi pekerjaan atap yang terdapat pada bangunan gedung dan ruko yang ditinjau.

Agar penelitian ini lebih fokus pada komponen penutup atap. Lingkup observasi penelitian ini pada 4 (empat) lokasi yaitu sebagai berikut:

1. Proyek Pembangunan Ruko jenis atap datar (plandak) dengan luas 4 x $25=100,00 \mathrm{~m}^{2} \mathrm{di}$ Meulaboh Aceh Barat;

2. Pembangunan Gedung Biro Rektorat \& Administrasi STKIP Bina Bangsa Getsempena Banda Aceh jenis atap datar (plandak) dengan luas $640 \mathrm{~m}^{2}$;

3. Pembangunan Gedung Kuliah STIKes Getsempena Lhoksukon Aceh Utara jenis atap pelana dengan luas $570,73 \mathrm{~m}^{2}$ dan

4. Pembangunan Gedung Rektorat STIKes Bina Nusantara Idi Aceh Timur jenis atap pelana dengan luas $711,65 \mathrm{~m}^{2}$.

Pengamatan tenaga kerja dilakukan pada jam 08.00-16.00 dengan istirahat satu jam yaitu jam 12.00-13.00. Obyek pengamatan hanya pada pekerjaan struktur rangka atap baja ringan.

\section{Pengumpulan Data}

Penelitian ini menggunakan dua jenis data yaitu data primer dan data sekunder. Data primer didapatkan melalui hasil observasi langsung di lapangan. Pencatatan dan pengukuran yang dilakukan terdiri dari pengukuran volume pekerjaan, pencatatan jumlah tenaga kerja, dan pengukuran waktu kerja efektif penyelesaian pekerjaan pada setiap segmen pekerjaan pemasangan/perakitan rangka atap. Data sekunder diperoleh dari dokumentasi proyek, berupa informasi seperti gambar rencana atap, daftar pekerjaan dan volume, dan Rencana Kerja dan Syarat-syarat (RKS). 


\section{Pengolahan Data dan Analisis}

Data yang telah terkumpul diolah untuk mendapatkan nilai produktivitas. Pengolahan data diawali dengan membuat pengelompokan data sesuai dengan lokasi pekerjaan pemasangan/perakitan rangka atap. Data volume, jumlah tenaga kerja, dan waktu efektif (waktu kerja efektif 8 jam/hari) menjadi masukan untuk mendapatkan nilai produktivitas. Proses analisis dilakukan dengan menggunakan persamaan diatas. Nilai produktivitas secara keseluruhan akan ditentukan berdasarkan nilai rerata yang diperoleh dari 4 lokasi tinjauan.

\section{HASIL DAN PEMBAHASAN}

\section{Hasil Observasi Lapangan}

Pelaksanaan pekerjaan pemasangan/perakitan rangka atap dilakukan pada 4 lokasi atap bangunan. Material rangka atap baja ringan yang digunakan adalah BJLAS (Baja Lapis Alumunium Seng) jenis C Truss 75 Tebal 0.75. Gambar rencana pemasangan dan dimensi material dapat dilihat pada Gambar 1 dan Gambar 2. Proses pembuatan/perakitan rangka atap baja ringan dapat dilihat pada Gambar 3.

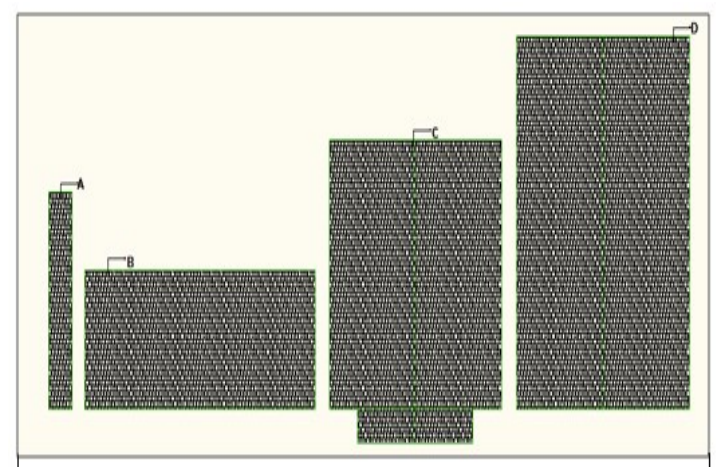

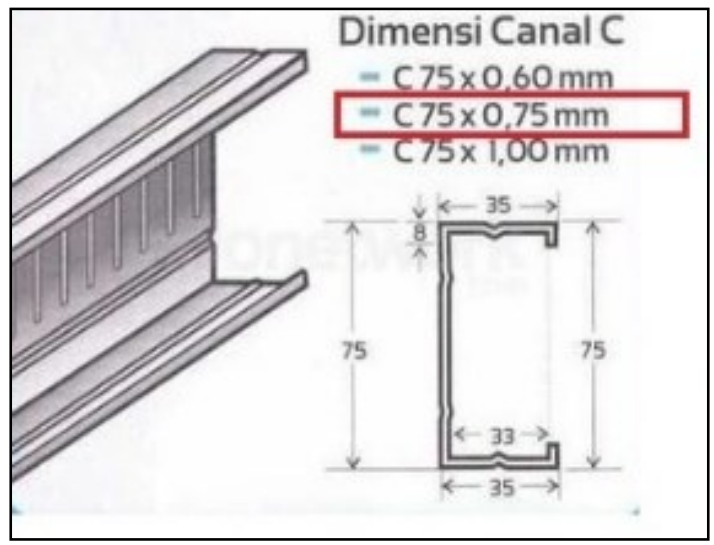

Gambar 2. Dimensi Material

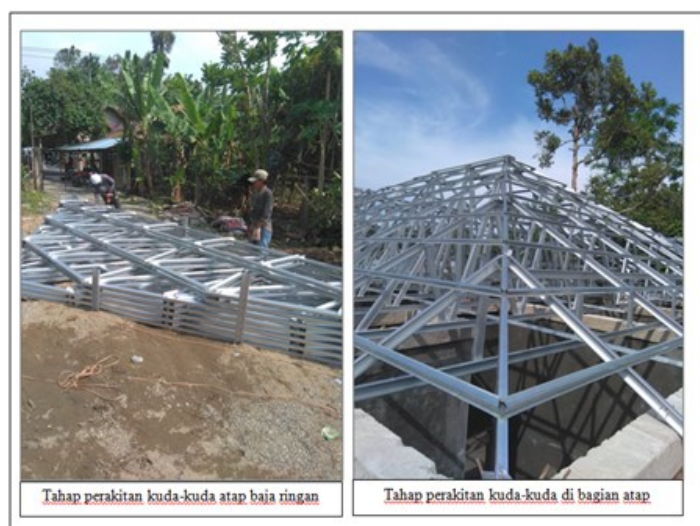

Gambar 3. Tahap Pekerjaan perakitan kuda-kuda atap baja ringan

\section{Produktivitas Pekerjaan}

Nilai produktivitas ditentukan oleh jumlah volume pekerjaan, jumlah pekerja, dan waktu kerja yang efektif. Analisis produktivitas kerja dari pekerjaan rangka atap baja ringan dimulai dengan menghitung volume pekerjaan yang dibahas sebelumnya. Kemudian dibandingkan dengan waktu kerja efektif dalam menyelesaikan pekerjaan di setiap lokasi pekerjaan rangka atap baja ringan. Hasil produktivitas di setiap lokasi pekerjaan rangka atap baja ringan dapat dilihat pada Tabel 1.

Gambar 1. Rencana Atap 
Tabel 1 Hasil produktivitas di setiap lokasi

\begin{tabular}{cccccccc}
\hline \multirow{2}{*}{ No } & $\begin{array}{c}\text { Lokasi } \\
\text { Pekerjaan }\end{array}$ & Volume & Tenaga Kerja & \multicolumn{2}{c}{ Waktu Efektif } & \multicolumn{2}{c}{ Produktivitas } \\
\cline { 3 - 8 } & & $\mathrm{m} 2$ & (orang) & (menit) & (jam) & (m2jam) & (m2hari) \\
\hline $\mathbf{1}$ & Lokasi A & 100.00 & 4 & 675 & 11.250 & 2.222 & 17.778 \\
\hline $\mathbf{2}$ & Lokasi B & 640.00 & 4 & 4420 & 73.667 & 2.172 & 17.376 \\
\hline $\mathbf{3}$ & Lokasi C & 570.73 & 4 & 4465 & 74.417 & 1.917 & 15.339 \\
\hline $\mathbf{4}$ & Lokasi D & 711.65 & 4 & 5508 & 91.800 & 1.938 & 15.504 \\
\hline \multicolumn{7}{c}{ Rata-rata } \\
\end{tabular}

Hasil analisis menunjukkan bahwa nilai produktivitas untuk pekerjaan rangka atap diperoleh rata-rata sebesar $2,062 \mathrm{~m}^{2} / \mathrm{jam}$ atau $16,499 \mathrm{~m}^{2} /$ hari. Nilai produktivitas dapat dikelompokkan menjadi 2 kelompok yaitu rangka atap jenis atap datar (plandak) lokasi A dan $\mathrm{B}$ dan rangka atap jenis pelana lokasi $\mathrm{C}$ dan D. Untuk lokasi A dan B jenis datar (plandak) nilai produktivitasnya lebih besar dari jenis atap pelana di lokasi C dan D, dikarenakan perakitannya lebih mudah dan memerlukan waktu kerja lebih sedikit. Pada pelaksanaan pekerjaan rangka atap, jumlah tenaga kerja yang digunakan sama pada seluruh segmen, sehingga nilai produktivitas cenderung ditentukan oleh besaran rasio antara volume pekerjaan dan waktu efektif pelaksanaan. Dengan demikian, bila jumlah volume pekerjaan dapat diselesaikan dalam waktu yang lebih singkat maka nilai produktivitas akan meningkat

\section{KESIMPULAN DAN SARAN}

\section{Kesimpulan}

Dari hasil analisis yang telah dilakukan, penelitian ini menyimpulkan bahwa untuk pekerjaan rangka atap, nilai produktivitas ratarata yang diperoleh sebesar $2,062 \mathrm{~m}^{2} / \mathrm{jam}$ atau $16,499 \mathrm{~m}^{2} /$ hari. Nilai produktivitas cenderung ditentukan oleh besaran rasio antara volume pekerjaan dan waktu efektif pelaksanaan. Hal ini disebabkan oleh penggunaan jumlah tenaga kerja yang sama pada setiap segmen tinjauan. Dengan demikian, bila jumlah volume pekerjaan dapat diselesaikan dalam waktu yang lebih singkat maka nilai produktivitas akan meningkat

\section{Saran}

Untuk kedepan atau penelitian selanjutnya agar bias dilakukan pada satu lokasi saja yang lumayan besar volume pekerjaan dan meliputi satu kesatuan pekerjaan rangka atap dan penutup atapnya. Supaya didapat nilai produktivitas secara keseluruhan baik nilai produktivitas rangka atap dan penutup atapnya sehingga dapat menjadi acuan lebih baik lagi dalam pekerjaan rangka atap dan penutup atap secara keseluruhannya.

\section{DAFTAR PUSTAKA}

Hansen. (2009). Menghitung Produktivitas Pekerja, https://hansenkammer.wordpress.com/ 2009/08/21/menghitung-produktivitaspekerja/, 15 Mei 201912.57 WIB

Kementerian Pekerjaan Umum. (2007). Peraturan Menteri Pekerjaan Umum Nomor : No.45/PRT/M/2007 Tentang Pedoman Teknis Pembangunan Bangunan Gedung Negara.

Kementerian Pekerjaan Umum. (2013).

Peraturan Menteri Pekerjaan Umum Nomor : No.11/PRT/M/2013 Tentang Pedoman Analisis Harga Satuan Pekerjaan Bidang Pekerjaan Umum. 
Kusjuliadi, D. (2007). Ragam Bentuk dan Perawatan Atap. Jakarta: Penebar Swadaya.

Mubarak., Fachrurrazi., Malahayati, Nurul., dan Ansari, Muhammad Gazi. (2015). Kajian Produktivitas Pada Pekerjaan Penutup Atap, Banda Aceh. Prosiding Seminar Nasional-Jurusan Teknik Sipil Unsyiah-Peran Inovasi Rekayasa Konstruk dalam Pembangunan Aceh yang Berkelanjutan.

Nurwibowo, Aditya. (2014). Analisis Produltivitas Pada Pemasangan Konstruksi Rangka Atap Baja Ringan. Fakultas Sipil dan Perencanaan Universitas Islam Indonesia, Yogyakarta.

Soedrajat, S. (1984). Analisa Anggaran Pelaksanaan. Bandung: Nova.

Tisnawan, Rahmat, Hadi, Saiful. (2016). Analisa Produktivitas Tenaga Kerja dan Biaya Pada Pekerjaan Pasangan Rangka Atap Pada Pembangunan Perumahan Panam View Tipe 48, Universitas Abdurrab. Jurnal Teknik Sipil Universitas Abdurrab. 1(2).

- How to cite this paper :

Mulyadi, M., Hasnawati, H., \& Ridha, M. (2019). Analisa Produktivitas Tenaga Kerja Pada Pekerjaaan Rangka Atap. Jurnal Teknik Sipil Unaya, 5(2), 68-75 